\title{
The Role of Front Line Service Employee in Select Service Industries in India
}

\author{
Ritu Srivastava*
}

\section{Abstract}

Employee actions form a very important aspect of service delivery. It is the employee who is reflected as the organization across and along with the various touch points to the customers. The Indian services sector hosts a lot of industries and dynamics within each are undergoing change. However, the understanding and knowledge of critical customer behavior does cut across industries and enable firms towards success. The role of the employee is the key to success especially in the high customer contact service industries as the employee actions convey the professionalism, sincerity and seriousness expected from a company towards understanding its customer base. Researchers in the developed world have done studies but the literature developed in the West cannot be adopted to the Indian context. Research studies done in other countries need to be replicated to see if the findings are applicable in the changed context and condition and only then be generalized. This is very important as businesses in the marketplace may tend to build strategies based on literature and experience established in a different context. This research study is an attempt to analyze the impact that employee actions have on customers in select service industries in India. For the purpose of this study the service employee has been confined to the front line staff in the Retail, Hospital, Airlines, Hotels and Banking industries.

* Assistant Professor, Marketing, Management Development Institute Mehrauli Road, Sukhrali, Gurgaon, Haryana. India;

ritu.srivastava@mdi.ac.in 
Keywords: Services marketing, India, emerging markets, Employee behavior, Customer satisfaction

\section{Introduction}

\section{The importance of employee actions}

Employee actions form a very important aspect of service delivery. Given the intrinsic nature of service characteristics, services being intangible, perishable, heterogeneous and with simultaneous production and consumption employee actions become all the more important as they counter these characteristics. It is the employee who is reflected as the organization across and along with the various touch points to the customers. For a customer to be satisfied, especially in India due to the collectivist culture, he must be able to get satisfactory responses from the company representative, whatever is the industry. The Indian services sector contributes to nearly two-thirds of India's economic output and one-third of its employed labor force. Services are an important contributor to international trade. With fresh economic reforms, the country's service sector is now open to the world to serve both as markets and businesses. It is imperative now that the sector must have an understanding of its customer and how it can differentiate its market offerings to counter the competition that is towards maturity. The services sector hosts a lot of industries and dynamics within each that is susceptible to change. However, the understanding and knowledge of critical customer behavior will cut across industries and enable firms towards success. The role of employee is the key especially in the high customer contact service industries. The Employee and Customer interaction is important and has received much attention in literature but the exact employee actions in the context of different countries has not been explored. Employee actions are very important because in the absence of any tangible feature they convey the professionalism, sincerity and seriousness expected from a company towards understanding its' customer base. Researchers in the developed world have done studies on the topic as mentioned in the section on literature review but it is done on an isolated basis in India. The literature developed in the West cannot be adopted to the Indian 
context as it is. Research studies done in other countries need to be replicated to see if the findings are applicable in the changed context and condition and only then be generalized. This is very important as businesses in the marketplace may tend to build strategies based on literature and experience established in a different context. This research study is an attempt to analyze the impact that employee actions have on customers in select service industries in India. Although anybody in a company is a service employee but for the purpose of this study we only take the front line staff in the Retail, Hospital, Airlines, Hotels and Banking industries.

\section{Literature Review}

Service encounter is the key component in the service consumption experience, of service companies (Gabbott and Hogg, 1998). The service encounter is the period of time during which the customer directly interacts with some aspect of the service organization, often in a marketer controlled environment (Fisk et al 2007). A service experience comprises four parts namely - the service workers, the service setting, the service consumers, and the service process. The bundle of service benefits a customer receives grows out of the interaction with the contact personnel and the inanimate service environment (Fisk et al., 2007).

The service-encounter failure is the second most important reason for switching service (Keaveney, 1995) and service quality perceptions and customer satisfaction are largely dependent on frontline employee service delivery behaviours such as courtesy, personal attentiveness, responsiveness, and keeping promises (Aldrich and Herker, 1977; Zeithaml et al., 1988). Thus, service encounter can get positively or negatively influenced by service worker behaviour. The service encounter/interaction between a service provider and customer has received attention in the marketing and management literature (Murray et al., 1996; Price et al., 1995; Chandon et al., 1997; Dobni et al., 1997). However, still little is known about the details of how consumers evaluate encounters. While much research has been done to better understand the components of service quality and the service 
encounter, little research has systematically explored what these components really mean to the consumer in terms of actual behaviors of service delivery personnel (Boulding et al., 1993, Winsted, 2000).

Parasuraman et al.'s $(1985,1988)$ SERVQUAL scale has provided very helpful insight regarding the dimensions of service quality; but confusion still exists about the meanings and relatedness of some of the constructs identified (Carman, 1990; Cronin and Taylor, 1992; Boulding et al., 1993). SERVQUAL would imply that a service provider should be courteous, empathetic, and helpful (among other things). However, they do not offer any insight into what this means to consumers, that is, what consumers want waiters, doctors, tellers and other service providers actually to do. Understanding these critical behaviors is the focus of this research and is the key to the ability of service providers to deliver service encounters that will lead to satisfied customers. Service providers need to have a better understanding of the attributes customers use to judge their performance in service encounters (Bowers et al., 1994; Peyrot et al., 1993) to excel in the process dimension for service quality. To effectively manage service encounters, managers need to develop operational definitions of constructs based on the behaviors of service delivery personnel, and to specify levels of appropriate performance (Bowers et al., 1994). However, the measures are generally informally derived and are often forced to fit SERVQUAL or other preconceived dimensions. Bitner et al. (1990) make great contributions by identifying behaviors that serve as critical incidents leading to very satisfactory or very unsatisfactory service encounters. In the Indian context studies have focused on employee behavior and customer satisfaction in specific settings, behavioral intentions etc. This study would focus on the front line employee actions in five service industries that could impact customers taking a cue from a study done in USA in 2000. Winsted, 2000 in a study on service behaviors that create customer satisfaction through every day evaluation of identified service employee actions; positive and negative that had an impact on customer satisfaction in the medical and restaurant setting with a group of MBA students in USA. The actions that correlated highly with customer satisfaction were factor analyzed for dimension reduction. Three factors covering 59 actions were 
identified that lead to customer satisfaction. These factors are; Concern, Civility and Congeniality. Future directions for the study are - to do this in a different country, with a different group of customers across different sectors. While there have been studies across the globe on the concept of employee behavior and customer satisfaction citing this study, there has been no study by changing the three conditions.

\section{Research Objectives}

This research study examines the impact of select 59 employee actions on the customer in changed conditions, across five service industries in India. The impact will be measured through the level of customer satisfaction achieved. The specific research objectives are:

i. How do the select employee actions impact customer satisfaction in India across select service industries?

ii. Are the results similar to previous established results in a different country?

iii. Can these actions play a role in predicting customer satisfaction in India?

\section{Research Outcome}

The study results would throw light on whether the Indian customer across this set of industries even value customer actions. In case he does, it has an impact on customer satisfaction. This finding will be important for the Indian service industry to assess their efforts against their employee actions. The findings of the second objective would help compare the results of the select employee actions on customer satisfaction to the results as obtained in the USA context. The role of employee actions in predicting customer satisfaction can then be explored as the third objective. With these results the retail industry will get a base to direct their efforts and money in a direction to achieve customer satisfaction and associated benefits. 


\section{Methodology}

The study was designed as a cross sectional descriptive study executed in the National Capital region (NCR) of New Delhi, India, with a total of 969 customers across five service industries; retail banking, hospitals, retail, airlines and hotels. On an average 200 customers from each industry were surveyed. Incomplete / missing responses were deleted. The data was collected through a "Customer Intercept Survey", at hospitals, hotels, retail stores, airport and bank branches by trained MBA student enumerators who were specializing in Services Management. The survey instrument was a questionnaire that was prepared in consultation with industry and with the help of academic literature in the domain with the base as the Winsted, 2000 study. The Cronbach alpha for the questionnaire was 0.91 . The data was collected in the form of score on seven point Likert type scale through individual interview using a questionnaire from 969 respondents. Data was collected both on employee actions and customer satisfaction through a single questionnaire. The collected data from the questionnaires were filtered out for missing values, duplication and other anomalies.

\section{Analysis}

The most common measure of dependence between two quantities is the Pearson product-moment correlation coefficient, or "Pearson's correlation coefficient", commonly called simply "the correlation coefficient". It is obtained by dividing the covariance of the two variables by the product of their standard deviations.

The population correlation coefficient $\rho_{X, Y}$ between two random variables $X$ and $Y$ with expected values $\mu_{X}$ and $\mu_{Y}$ and standard deviations $\sigma_{X}$ and $\sigma_{Y}$ is defined as:

$$
\rho_{X, Y}=\operatorname{corr}(X, Y)=\frac{\operatorname{cov}(X, Y)}{\sigma_{X} \sigma_{Y}}=\frac{E\left[\left(X-\mu_{X}\right)\left(Y-\mu_{Y}\right)\right]}{\sigma_{X} \sigma_{Y}},
$$

Where $E$ is the expected value operator, cov means covariance, and, corr a widely used alternative notation for the correlation coefficient. 
The Pearson correlation is defined only if both of the standard deviations are finite and both of them are nonzero. The correlation coefficient is symmetric: $\operatorname{corr}(X, Y)=\operatorname{corr}(Y, X)$.

The Pearson correlation is +1 in the case of a perfect positive (increasing) linear relationship (correlation), -1 in the case of a perfect decreasing (negative) linear relationship (anticorrelation), ${ }^{[5]}$ and some value between -1 and 1 in all other cases, indicating the degree of linear dependence between the variables. As it approaches zero there is less of a relationship (closer to uncorrelated). The closer the coefficient is to either -1 or 1 , the stronger the correlation between the variables.

If the variables are independent, Pearson's correlation coefficient is 0 , but the converse is not true because the correlation coefficient detects only linear dependencies between two variables. For example, suppose the random variable $X$ is symmetrically distributed about zero, and $Y=X^{2}$. Then $Y$ is completely determined by $X$, so that $X$ and $Y$ are perfectly dependent, but their correlation is zero; they are uncorrelated. However, in the special case when $X$ and $Y$ are jointly normal, un-correlatedness is equivalent to independence.

If we have a series of $n$ measurements of $X$ and $Y$ written as $x_{i}$ and $y_{i}$ where $i=1,2, \ldots, n$, then the sample correlation coefficient can be used to estimate the population Pearson correlation $r$ between $X$ and $Y$. The sample correlation coefficient is written

$$
r_{x y}=\frac{\sum_{i=1}^{n}\left(x_{i}-\bar{x}\right)\left(y_{i}-\bar{y}\right)}{(n-1) s_{x} s_{y}}=\frac{\sum_{i=1}^{n}\left(x_{i}-\bar{x}\right)\left(y_{i}-\bar{y}\right)}{\sqrt{\sum_{i=1}^{n}\left(x_{i}-\bar{x}\right)^{2} \sum_{i=1}^{n}\left(y_{i}-\bar{y}\right)^{2}}},
$$

where $\mathrm{x}$ and $\mathrm{y}$ are the sample means of $X$ and $Y$, and $s_{x}$ and $s_{y}$ are the sample standard deviations of $X$ and $Y$.

This can also be written as: 


$$
r_{x y}=\frac{\sum x_{i} y_{i}-n \bar{x} \bar{y}}{(n-1) s_{x} s_{y}}=\frac{n \sum x_{i} y_{i}-\sum x_{i} \sum y_{i}}{\sqrt{n \sum x_{i}^{2}-\left(\sum x_{i}\right)^{2}} \sqrt{n \sum y_{i}^{2}-\left(\sum y_{i}\right)^{2}}} .
$$

If $x$ and $y$ are results of measurements that contain measurement error, the realistic limits on the correlation coefficient are not -1 to +1 but a smaller range. ${ }^{[6]}$

For the case of a linear model with a single independent variable, the coefficient of determination ( $R$ squared) is the square of $r$, Pearson's product-moment coefficient.

In this study, we adopt the service encounter dimensions that emerged from Winsted's (2000) study of USA MBA students' sample, as well as the items associated with them. Winsted (2000) followed a systematic procedure in identifying a substantial pool of behaviors that could serve as measurements for service encounter components. The study uses the 59 variables (employee positive and negative actions that are important in a service encounter). These 59 variables are key front line employee actions identified as the key behaviors across the medical and restaurant industry and have a Pearson correlation factor $\mathrm{r}$ of 0.5 or more with customer encounter satisfaction in the study on employee actions that lead to customer satisfaction by Winsted, 2000. In the Indian context also these 59 actions show significant correlation with customer satisfaction as highlighted in Table 1; at 95\% confidence interval across five service industries but the strength of the correlation if observed, does not even have one action that has a correlation equal to or greater than 0.5 with satisfaction. It may thus be that the Indian customer does give value to these frontline service employee actions.

Table 1 Results of Correlation Analysis on Customer Satisfaction

\begin{tabular}{|l|c|c|}
\hline \multicolumn{3}{|c|}{ Correlations } \\
\hline \hline Employee actions & Pearson Correlation & Significance \\
\hline \hline Was Attentive & .401 & .000 \\
\hline \hline No Sense Of Humour & -.065 & .047 \\
\hline \hline Acted Rudely & -.198 & .000 \\
\hline \hline Was friendly & .344 & .000 \\
\hline \hline Quick Response & .419 & .000 \\
\hline \hline Considered me & .242 & .000 \\
\hline
\end{tabular}




\begin{tabular}{|c|c|c|}
\hline Seemed intelligent & .372 & .000 \\
\hline Sincere body language & .396 & .000 \\
\hline Available & .267 & .000 \\
\hline Seemed distracted & -.170 & .000 \\
\hline Seemed natural and genuine & .271 & .000 \\
\hline Acted in a Relaxed manner & .145 & .000 \\
\hline Answered all the questions & .340 & .000 \\
\hline Indifferent & -.078 & .017 \\
\hline Knowledgeable & .237 & .000 \\
\hline Provided bad service & -.366 & .000 \\
\hline Ignored me & -.244 & .000 \\
\hline Seemed honest & .331 & .000 \\
\hline Was sincere & .405 & .000 \\
\hline Anticipated my need & .327 & .000 \\
\hline Sincere face expressions & .263 & .000 \\
\hline Did not provide complete service & -.202 & .000 \\
\hline Seemed to have good manners & .375 & .000 \\
\hline Was very personable & .243 & .000 \\
\hline Did not smile & -.095 & .003 \\
\hline Worked to resolve any problems & .321 & .000 \\
\hline Asked me how I was & .278 & .000 \\
\hline Eye contact & .240 & .000 \\
\hline Seemed happy and cheerful & .329 & .000 \\
\hline Was helpful & .421 & .000 \\
\hline Listened to what I have to say & .380 & .000 \\
\hline $\begin{array}{l}\text { Seemed interested in my talks and } \\
\text { needs }\end{array}$ & .386 & .000 \\
\hline Was nice to me & .444 & .000 \\
\hline Was very enthusiastic & .329 & .000 \\
\hline Talked to me & .306 & .000 \\
\hline Was very courteous & .362 & .000 \\
\hline Acted in a personal way & .272 & .000 \\
\hline Was very pleasant & .367 & .000 \\
\hline Did not look in the eyes & -.039 & .231 \\
\hline Made me feel comfortable & .390 & .000 \\
\hline Was very competent & .346 & .000 \\
\hline Was very professional & .322 & .000 \\
\hline Engaged in small talk & .074 & .023 \\
\hline Smiled a lot & .156 & .000 \\
\hline Granted my special request & .309 & .000 \\
\hline Was Annoyed & -.210 & .000 \\
\hline
\end{tabular}




\begin{tabular}{|l|c|c|}
\hline Acted arrogantly & -.246 & .000 \\
\hline Was very warm & .156 & .000 \\
\hline Was very abrupt & -.171 & .000 \\
\hline \hline Seemed distant & -.254 & .000 \\
\hline Had a bad attitude & -.309 & .000 \\
\hline \hline Seemed to be interested in business & -.205 & .000 \\
\hline Treated me as a number & -.237 & .000 \\
\hline Answered all my questions & .363 & .000 \\
\hline \hline Seemed to care about me & .437 & .000 \\
\hline Was very stiff & -.140 & .000 \\
\hline Respected me & .429 & .000 \\
\hline Took The Time To Perform Service & -.103 & .000 \\
\hline Provided A Bad Service & -.366 & .002 \\
\hline
\end{tabular}

* (-) sign shows negative employee actions

Table 2 Comparative Results of Correlation Analysis on Customer Satisfaction in the Indian context with the USA Medical Services

\begin{tabular}{|l|c|c|}
\hline Employee actions & $\begin{array}{c}\text { Pearson } \\
\text { Correlation }\end{array}$ & $\begin{array}{c}\text { USA } \\
\text { Medical } \\
\text { Industry }\end{array}$ \\
\hline Was Attentive & .401 & .071 \\
\hline No Sense Of Humour & -.065 & 0.58 \\
\hline Acted Rudely & -.198 & 0.53 \\
\hline Was friendly & .344 & 0.66 \\
\hline Quick Response & .419 & 0.63 \\
\hline Considered me & .242 & 0.53 \\
\hline Seemed intelligent & .372 & 0.62 \\
\hline Sincere body language & .396 & 0.53 \\
\hline Available & .267 & 0.55 \\
\hline Seemed distracted & -.170 & 0.59 \\
\hline Seemed natural and genuine & .271 & 0.66 \\
\hline Acted in a Relaxed manner & .145 & 0.55 \\
\hline Answered all the questions & .340 & 0.61 \\
\hline Indifferent & -.078 & 0.55 \\
\hline Knowledgeable & .237 & 0.55 \\
\hline Provided bad service & -.366 & 0.59 \\
\hline Ignored me & -.244 & 0.56 \\
\hline Seemed honest & .331 & 0.53 \\
\hline Was sincere & .405 & 0.76 \\
\hline
\end{tabular}




\begin{tabular}{|l|c|c|}
\hline Anticipated my need & .327 & 0.52 \\
\hline Sincere face expressions & .263 & 0.69 \\
\hline Did not provide complete service & -.202 & 0.57 \\
\hline Seemed to have good manners & .375 & 0.65 \\
\hline Was very personable & .243 & 0.73 \\
\hline Did not smile & -.095 & 0.61 \\
\hline Worked to resolve any problems & .321 & 0.60 \\
\hline Asked me how I was & .278 & 0.57 \\
\hline Eye contact & .240 & 0.52 \\
\hline Seemed happy and cheerful & .329 & 0.61 \\
\hline Was helpful & .421 & 0.68 \\
\hline Listened to what I have to say & .380 & 0.58 \\
\hline Seemed interested in my talks and needs & .386 & 0.67 \\
\hline Was nice to me & .444 & 0.74 \\
\hline Was very enthusiastic & .329 & 0.54 \\
\hline Talked to me & .306 & 0.60 \\
\hline Was very courteous & .362 & 0.65 \\
\hline Acted in a personal way & .272 & 0.71 \\
\hline Was very pleasant & .367 & 0.75 \\
\hline Did not look in the eyes & -.039 & 0.61 \\
\hline Made me feel comfortable & .390 & 0.74 \\
\hline Was very competent & .346 & 0.64 \\
\hline Was very professional & .322 & 0.58 \\
\hline Engaged in small talk & .074 & 0.50 \\
\hline Smiled a lot & .156 & 0.50 \\
\hline Granted my special request & .309 & 0.53 \\
\hline Was Annoyed & -.210 & 0.56 \\
\hline Acted arrogantly & -.246 & 0.54 \\
\hline Was very warm & .156 & 0.66 \\
\hline Was very abrupt & -.171 & 0.58 \\
\hline Seemed distant & -.254 & 0.68 \\
\hline Had a bad attitude & -.309 & 0.58 \\
\hline Seemed to be interested in business & -.205 & 0.55 \\
\hline Treated me as a number & -.237 & 0.62 \\
\hline Answered all my questions & .363 & 0.61 \\
\hline Seemed to care about me & .437 & 0.78 \\
\hline Was very stiff & -.140 & 0.58 \\
\hline Respected me & .429 & 0.61 \\
\hline Took The Time To Perform Service & -.103 & 0.60 \\
\hline Provided A Bad Service & -.366 & 0.59 \\
\hline
\end{tabular}


Table 3: Comparative Results of Correlation Analysis on Customer Satisfaction in the Indian context USA Restaurant Services

\begin{tabular}{|l|c|c|}
\hline \multicolumn{1}{|c|}{ Employee actions } & $\begin{array}{c}\text { Pearson } \\
\text { Correlation }\end{array}$ & $\begin{array}{c}\text { USA } \\
\text { Restaurant } \\
\text { Industry }\end{array}$ \\
\hline \hline Was Attentive & .401 & 0.78 \\
\hline No Sense Of Humour & -.065 & 0.63 \\
\hline \hline Acted Rudely & -.198 & 0.57 \\
\hline Was friendly & .344 & 0.70 \\
\hline Quick Response & .419 & 0.67 \\
\hline \hline Considered me & .242 & 0.55 \\
\hline Seemed intelligent & .372 & 0.65 \\
\hline Sincere body language & .396 & 0.59 \\
\hline \hline Available & .267 & 0.67 \\
\hline Seemed distracted & -.170 & 0.66 \\
\hline \hline Seemed natural and genuine & .271 & 0.66 \\
\hline Acted in a Relaxed manner & .145 & 0.56 \\
\hline \hline Answered all the questions & .340 & 0.54 \\
\hline \hline Indifferent & -.078 & 0.61 \\
\hline Knowledgeable & .237 & 0.59 \\
\hline \hline Provided bad service & -.366 & 0.68 \\
\hline Ignored me & -.244 & 0.59 \\
\hline Seemed honest & .331 & 0.58 \\
\hline Was sincere & .405 & 0.69 \\
\hline Anticipated my need & .327 & 0.65 \\
\hline \hline Sincere face expressions & .263 & 0.70 \\
\hline Did not provide complete service & -.202 & 0.63 \\
\hline \hline Seemed to have good manners & .375 & 0.73 \\
\hline Was very personable & .243 & 0.69 \\
\hline Did not smile & -.095 & 0.63 \\
\hline Worked to resolve any problems & .321 & 0.60 \\
\hline Asked me how I was & .278 & 0.55 \\
\hline \hline Eye contact & .240 & 0.56 \\
\hline Seemed happy and cheerful & .329 & 0.69 \\
\hline Was helpful & .421 & 0.69 \\
\hline Listened to what I have to say & .380 & 0.57 \\
\hline \hline Seemed interested in my talks and \\
needs & .386 & 0.68 \\
\hline \hline Was nice to me & .444 & 0.72 \\
\hline Was very enthusiastic & .329 & 0.67 \\
\hline
\end{tabular}




\begin{tabular}{|l|c|c|}
\hline Talked to me & .306 & 0.54 \\
\hline \hline Was very courteous & .362 & 0.70 \\
\hline \hline Acted in a persona lway & .272 & 0.65 \\
\hline \hline Was very pleasant & .367 & 0.76 \\
\hline \hline Did not look in the eyes & -.039 & 0.58 \\
\hline \hline Made me feel comfortable & .390 & 0.73 \\
\hline \hline Was very competent & .346 & 0.66 \\
\hline \hline Was very professional & .322 & 0.60 \\
\hline \hline Engaged in small talk & .074 & 0.51 \\
\hline \hline Smiled a lot & .156 & 0.58 \\
\hline \hline Granted my special request & .309 & 0.55 \\
\hline \hline Was Annoyed & -.210 & 0.54 \\
\hline \hline Acted arrogantly & -.246 & 0.51 \\
\hline \hline Was very warm & .156 & 0.71 \\
\hline \hline Was very abrupt & -.171 & 0.55 \\
\hline \hline Seemed distant & -.254 & 0.63 \\
\hline \hline Had a bad attitude & -.309 & 0.60 \\
\hline \hline Seemed to be interested in & -.205 & 0.59 \\
\hline \hline business & -.237 & 0.66 \\
\hline \hline Treated me as a number & .363 & 0.54 \\
\hline \hline Answered all my questions & .437 & 0.65 \\
\hline \hline Was very stiff & -.140 & 0.62 \\
\hline \hline Respected me & .429 & 0.58 \\
\hline \hline Took The Time To Perform Service & -.103 & 0.65 \\
\hline \hline Provided A Bad Service & -.366 & \\
\hline
\end{tabular}

\section{Interpretation of the Results}

The results of the correlation analysis and the comparison to the USA medical and restaurant industry bring out a contrast in the findings. As can be seen from Table 2 and 3 all the 59 positive and negative employee actions have a correlation of more than 0.5 with customer satisfaction in the USA context. The correlation table gives us a very important and critical insight into customer's perception of employee actions that may give a different result in a different context. These employee actions may be solicited and noticed by the Indian customer but they are not important enough to lead to satisfaction, whereas they are important for customer satisfaction in USA assuming the linear relationship between the 
factors as done in the Winsted study. Winsted in her study has mentioned to repeat the study with a different group of customers, across service industries in different country contexts. With the kinds of results observed from the correlation analysis building on these employee actions to lead towards customer satisfaction may not yield the desired results in the Indian context rather these actions may be acting as satisfiers and absence of them would be a dissatisfier. The need today is to understand what the Indian service customer would want from employee in terms of actions and the plot may be laid fresh.

\section{Managerial Implications}

\section{To summarize}

The Indian Service Customer gives weightage to the employee actions as observed through the significance levels for the correlation analysis so the Indian service managers must realize that employee actions are important to be noticed for customer attention and efforts are to be put in. Howeve, as the value of the correlation coefficient is very low and in contrast to the values in the USA context, the real need of the hour is to identify what could impact customer satisfaction in terms of front line service employee action as experience from the West needs to adapted in the Indian conditions and not enforced as it is.

\section{Conclusion}

Field studies done in the area of consumer and employee behavior in specific cultures and contexts have to be validated before generalizing them across cultures contexts. As soon as the base country conditions change the results change significantly, appropriate corporate and marketing strategies by both local and foreign competition in a specific location context needs to appreciated and reworked.

\section{Future Directions}

This study is just the beginning; what is needed today is to draw upon the established services marketing literature available and test that in our Indian conditions as done in the study. The next step should be to start exploring the employee actions that would 
impact customer satisfaction in Indian conditions. Future research should work in tandem with the customer and service companies in India.

\section{Assumption}

A linear relationship between service employee behavior and customer satisfaction is taken as in the base study by Winsted (2000).

\section{References}

Aldrich, H. \& Herker, D. (1977). Boundary spanning roles and organizational structure. Academy of Management Review, 2, 217-30.

Bitner, M. J., Booms, B. \& Tetreault, M. (1990). The service encounter: Diagnosing favorable and unfavorable incidents. Journal of Marketing, 54 (1), 71-84.

Boulding, W., Kalra, A., Staelin, R. \& Zeithaml, V. (1993). A dynamic model of service quality: From expectations to behavioral intentions. Journal of Marketing Research, 30 (2), 7-27.

Bowers, M., Swan, J. \& Koehler, W. (1994). What attributes determine quality and satisfaction with health-care delivery?. Health Care Management Review, 19(3).

Carman, J. (199). Consumer perceptions of service quality: An assessment of the SERVQUAL dimensions. Journal of Retailing, 66(2), 33-55.

Chandon, J. L., Leo, P. Y. \& Philippe, J. (1997). Service encounter dimensions \pm a dyadic perspective: Measuring the dimensions of service encounters as perceived by customers and personnel. International Journal of Service Industry Management, 8(1), 65-86.

Cronin, J. J. Jr \& Taylor, S. A. (1992). Measuring service quality: A reexamination and extension. Journal of Marketing, 56, 55-68.

Dobni, D., Zerbe, W. \& Ritchie, J. R. B. (1997). Enhancing service personnel effectiveness through the use of behavioral repertoires. Journal of Services Marketing,11(6), 427-45.

Fisk, R. P., Grove, S. J. \& John, J. (2007). Interactive Services Marketing, 3rd ed., South-Western College, Chula Vista, CA.

Gabbott, M. \& Hogg, G. (1998). Consumers and Services, Wiley, Chichester.

Keaveney, S. M. (1995). Customer switching behavior in service industries: An exploratory study. Journal of Marketing, 59(2), 71-82.

Murray, I., Wilcock, A. \& Kobayashi, L. (1996). Obstetrical patient satisfaction. Journal of Health Care Marketing, 16 (3), 54-7. 
Parasuraman, A., Zeithaml, V. \& Berry, L. (1985). A conceptual model of service quality and its implications for future research. Journal of Marketing, 49 (3), 41-50.

Parasuraman, A., Zeithaml, V. \& Berry, L. (1988). SERVQUAL: A multiple-item scale for measuring customer perceptions of service quality. Journal of Retailing, 64 (2),

Peyrot, M., Cooper, D. \& Schnapf, D. (1993). Consumer satisfaction and perceived quality of out-patient health services. Journal of Health Care Marketing, 13 (1), 24-33.

Price, L., Arnould, E. \& Tierney, P. (1995). Going to extremes: Managing service encounters and assessing provider performance. Journal of Marketing, 59 (2), 83-97.

Winsted, K. F. (2000). Service behaviors that lead to satisfied customers. European Journal of Marketing, 34 (3/4), 399-417.

Zeithaml, V. A., Berry, L. L. \& Parasuraman, A. (1988). Communication and control processes in the delivery of service quality. Journal of Marketing, 52, 35-48. 